\title{
ADICIONES A LAS CONNARACEAE DEL ESTADO DE GUERRERO, MÉXICO
}

\author{
JAIME JIMÉNEZ-RAMÍREZZ ${ }^{1,2}$ Y RAMIRO CRUZ-DURÁN ${ }^{1}$
}

${ }^{1}$ Universidad Nacional Autónoma de México, Facultad de Ciencias, Departamento de Biología Comparada, Apdo. postal 70-181, Delegación Coyoacán, 04510 México, D.F., México.

${ }^{2}$ Autor para la correspondencia: jjimenez_ramirez@yahoo.com

\section{RESUMEN}

Se presenta la adición de Connarus stenophyllus Standl. et L.O. Williams ex Ant. Molina y C. lentiginosus Brandegee a la flora del estado de Guerrero, México. Se incluye también la descripción de ambas especies y ejemplares de herbario estudiados, así como una clave para diferenciarlas.

Palabras clave: Connaraceae, Connarus, flora, Guerrero, México.

\section{ABSTRACT}

The addition of Connarus stenophyllus Standl. et L.O. Williams ex Ant. Molina and C. lentiginosus Brandegee to the flora of Guerrero state, Mexico, is presented. Descriptions of both species are given as well as a key to distinguish them; herbarium specimens studied are also included.

Key words: Connaraceae, Connarus, flora, Guerrero, Mexico.

En la revisión de las Connaraceae de Flora de Guerrero, Fonseca (2005) registró solo la presencia de Rourea glabra Kunth var. glabra. Sin embargo, en las exploraciones botánicas en el estado de Guerrero, efectuadas por personal del herbario FCME, se recolectó Connarus stenophyllus Standl. et L.O. Williams ex Ant. Molina, y al revisar el Herbario Nacional (MEXU) se halló 
un ejemplar de C. lentiginosus Brandegee, lo que coincide con lo reportado por Forero (2010).

Por ello, a continuación se presenta una clave modificada de Forero (2010) para la distinción entre los géneros Rourea y Connarus y la descripción de este último. Asimismo, se anexan las descripciones concisas de C. lentiginosus Brandegee y C. stenophyllus Standl. et L.O. Williams ex Ant. Molina, de acuerdo con los estándares de Flora de Guerrero y basadas en los ejemplares de tal estado depositados en FCME y MEXU y en Forero (2010); de igual forma, se proporciona una clave para distinguir ambas especies.

1 Gineceo con 5 carpelos libres; pétalos sin glándulas; frutos sésiles Rourea glabra Kunth var. glabra (ver Fonseca, 2005) 1 Gineceo unicarpelar; pétalos con puntos glandulosos; frutos estipitados

Connarus

Connarus L., Sp. Pl. 2: 675. 1753.

Especie tipo: Connarus monocarpos L.

Árboles pequeños, arbustos trepadores o bejucos; ramas con pelos simples o glandulosos. Hojas (1)3 a 5(9) folioladas, imparipinnadas, glabras o con el envés pubérulo. Inflorescencias en panículas axilares, terminales o pseudoterminales, ocasionalmente caulinares. Flores pediceladas; sépalos imbricados; pétalos y sépalos con puntos glandulosos; estambres 10, ligeramente connados en la base, glabros o con pelos glandulosos; gineceo unicarpelar, ovario súpero, con 2 óvulos. Fruto un folículo solitario, generalmente estipitado, glabro o con pelos interna o externamente. Semillas 1, endospermo ausente, con arilo evidente.

Connarus es un género de distribución pantropical con 80 a 100 especies (Forero, 1983).

Clave para las especies de Connarus en el estado de Guerrero.

1 Hojas (1)3 a 5 folioladas; folíolos (5)14.5 a 18(22) cm de largo y (2.3)5.6 a $7.4(8.5) \mathrm{cm}$ de ancho, con 7 a 10 pares de venas secundarias y envés puberulento; puntuaciones evidentes en envés de los folíolos; folículos $2.2 \mathrm{~cm}$ de largo y $1.4 \mathrm{~cm}$ de ancho C. lentiginosus 
1 Hojas trifolioladas; folíolos 5 a $13 \mathrm{~cm}$ de largo y (1.5)2.5 a $6 \mathrm{~cm}$ de ancho, con 5 a 7 pares de venas secundarias y glabros; puntuaciones ausentes en los folíolos; folículos (2.2)2.5 a $3.5 \mathrm{~cm}$ de largo y 1.4(1.7) a $2 \mathrm{~cm}$ de ancho .... C. stenophyllus

Connarus stenophyllus Standl. et L.O. Williams ex Ant. Molina, Ceiba 14(1): 2. 1968. Tipo: México, Chiapas, Los Lagos, Carlson 1860 (Holotipo: EAP).

Nombre común: "ts'oom tandoo" (amuzgo).

Árboles, arbustos o lianas de 5 a 8(10) $\mathrm{m}$ de alto. Hojas (11)13.5 a $21 \mathrm{~cm}$ de largo, glabras, con 3 folíolos; folíolos opuestos, subpeltados, 5 a $13 \mathrm{~cm}$ de largo, (1.5)2.5 a $6 \mathrm{~cm}$ de ancho, elípticos, glabros, con 5 a 7 pares de venas secundarias, base obtusa, haz y envés glabros, sin puntaciones, margen entero, ápice corta a largamente caudado, en ocasiones emarginado; raquis (10)15 a $23 \mathrm{~mm}$ de largo; peciólulos 3 a 4 $\mathrm{mm}$; pecíolo 3 a 5.5(7) cm de largo. Inflorescencias en panículas terminales, 11 a 17 $\mathrm{cm}$ de largo; raquis, pedicelos y brácteas ferrugíneas. Flores con pedicelos de $2 \mathrm{~mm}$ de largo; sépalos ovados, ferrugíneos, ápice agudo; pétalos con puntuaciones conspicuas, glabros; estambres glabros; pistilo viloso, estipitado. Folículos 2.5 a $3.5 \mathrm{~cm}$ de largo, 1.7 a $2 \mathrm{~cm}$ de ancho, rojos, glabros, aproximadamente obovados, aplanados, ápice con pico evidente; estípite de hasta $8 \mathrm{~mm}$ de largo, con una semilla. Semillas $1.6 \mathrm{~cm}$ de largo, $0.8 \mathrm{~cm}$ de ancho, oblongas, negras; arilo evidente, amarillo (Fig. 1).

Distribución: México (Chiapas, Guerrero, Oaxaca).

Ejemplares examinados: México. Guerrero, Mpio. Atoyac de Álvarez, Los Pilones, 4 may. 1984 (fruto, flor en botón), R. M. Fonseca, J. 541 (FCME); Mpio. Iliatenco, carretera a Iliatenco, 1658'59.6" N, 9840'41" O, 17 mar. 2012 (fruto), $J$. Jiménez y K. Vega 89-2012 (FCME); Mpio. San Luis Acatlán, 37 km adelante de San Luis Acatlán, rumbo a Iliatenco, 1984 (año probable; fruto), R. M. Fonseca 217 (FCME); $12.5 \mathrm{~km}$ al N de Horcasitas, camino San Luis Acatlán - El Potrero - El Rincón, 7 nov. 1983 (fruto), E. Martínez y F. Morales 3476 (MEXU); Mpio. Tlacochistlahuaca, $33 \mathrm{~km}$ al norte de Ometepec, camino a Tlacochistlahuaca - San Isidro, 26 nov. 1983 (fruto), E. Martinez y F. R. Barrie 5785 (MEXU); Tlacochistlahuaca, 6 km al N, 27 nov. 1983 (fruto), G. Campos R. 1052 (FCME); Xochistlahuaca, 16²47.4' N, 98¹4.1' O, may. 1986 (flor en botón), B. López s.n. (MO).

Altitud: (460)1000 a $1205 \mathrm{~m}$.

Tipo de vegetación: bosque mesófilo de montaña, bosque tropical subcaducifolio, bosque de Quercus. 
Acta Botanica Mexicana 106: $73-78$ (2014)

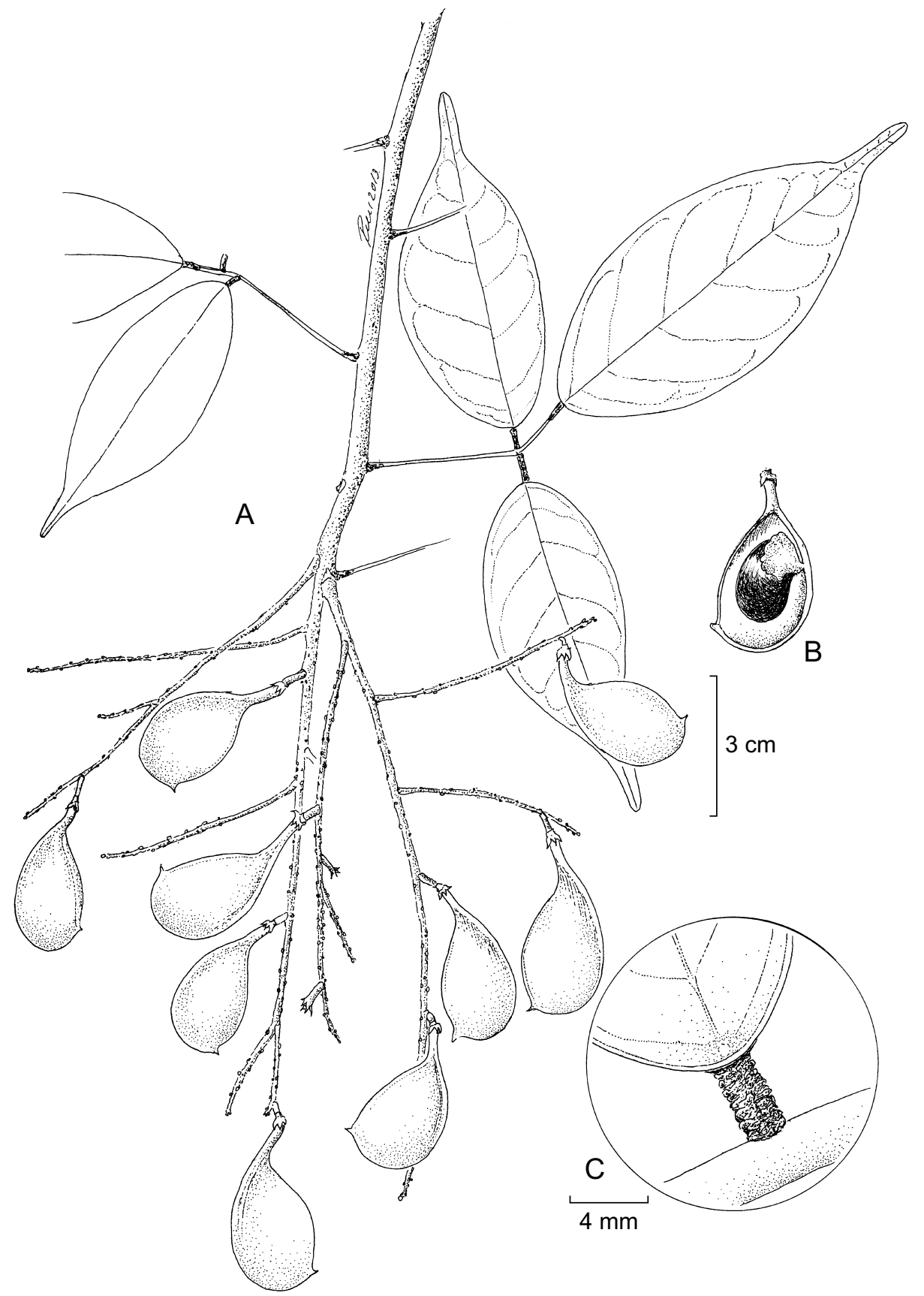

Fig. 1. Connarus stenophyllus Standl. et L.O. Williams ex Ant. Molina. A. rama con frutos; B. semilla; C. base del folíolo y peciólulo. Basados en J. Jiménez y K. Vega 89-2012, FCME. 
Fenología: florece en mayo y fructifica de noviembre a marzo.

Usos: se desconocen.

Connarus lentiginosus Brandegee, Univ. Calif. Publ. Bot. 6(8): 186. 1915. Tipo: México, Chiapas, Huitla y Finca Irlanda, Purpus 7379 (Holotipo: UC).

Nombre común: no registrado.

Árboles o bejucos leñosos. Hojas hasta $27.5 \mathrm{~cm}$ de largo, con (1)3 a 5 folíolos, glabras; folíolos (5)14.5 a 18(22) cm de largo, (2.3)5.6 a 7.4(8.5) cm de ancho, con 7 a 10 pares de venas secundarias, base cuneada, haz glabro, envés puberulento o glabro, con puntuaciones evidentes, margen entero, ápice acuminado; peciólulos 6 a $8 \mathrm{~mm}$ de largo; raquis 1.8 a $2 \mathrm{~cm}$ de ancho; pecíolo 10.5 a $12.5 \mathrm{~cm}$ de largo. Inflorescencias paniculadas, terminales, de hasta 10 cm de largo. Flores con pedicelos de 0.5 a $1 \mathrm{~cm}$ de largo; cáliz 2.8 a $3.5 \mathrm{~mm}$ de largo; sépalos triangulares, tomentosos externamente; pétalos 4.5 a $7 \mathrm{~mm}$ de largo, elípticos; estambres $3 \mathrm{~mm}$ de largo, glabros; pistilo densamente tomentoso, con puntuaciones rojas, ovario estipitado. Folículos (2.2) 2.5 a $3.5 \mathrm{~cm}$ de largo, (1.4)1.7 a $2 \mathrm{~cm}$ de ancho, engrosados, estípite $5 \mathrm{~mm}$ de largo, ápice redondo. Semillas no vistas.

Distribución: México (Chiapas, Guerrero, Oaxaca), Guatemala y Nicaragua.

Ejemplares examinados: Mpio. Petatlán, Rabo de Iguana, al $\mathrm{N}$ de Petatlán, bosque de pino-encino, nov. 1973 (fruto), F. González M. 6601 (MEXU).

Altitud: 0 a 1200(1800) $\mathrm{m}$.

Tipo de vegetación: bosque de pino.

Fenología: fructifica en noviembre.

Usos: se desconocen.

Forero (2010) describe a Connarus lentiginosus Brandegee como un bejuco leñoso, pero el único ejemplar registrado para el estado ( $F$. González $M$. 6601(MEXU)) señala que es un árbol, lo que podría deberse a una mala interpretación del colector.

Es relevante mencionar que las Connaraceae de Guerrero cuentan ahora con dos géneros que incluyen a tres especies, número idéntico a las conocidas para el estado de Oaxaca, de acuerdo con los datos de García-Mendoza y Meave (2012). 


\section{AGRADECIMIENTOS}

A Martha Martínez Gordillo y Susana Valencia Ávalos, por la revisión del manuscrito; a José Antonio Hernández, Laboratorio de Microcine, Facultad de Ciencias, Universidad Nacional Autónoma de México, por la digitalización de la figura 1 y a la Dirección General de Asuntos del Personal Académico de la Universidad Nacional Autónoma de México, por el apoyo económico al proyecto PAPIIT IN214112.

\section{LITERATURA CITADA}

Fonseca, R. M. 2005. Connaraceae y Resedaceae. Flora de Guerrero 25:1-10.

Forero, E. 1983. Connaraceae. Fl. Neotrop. 36: 37.

Forero, E. 2010. Connaraceae. In: Davidse, G., M. Sousa, S. Knapp y F. Chiang (eds.). Vitaceae a Geraniaceae. Flora Mesoamericana. Vol. 3, Núm. 1. Universidad Nacional Autónoma de México, México. (Publicada inicialmente en el sitio de internet de Flora Mesoamericana: http://www.tropicos.org/docs/meso/connaraceae.pdf).

García-Mendoza, A. J. y J. A. Meave. 2011. Diversidad florística de Oaxaca: de musgos a angiospermas (colecciones y lista de especies). Universidad Nacional Autónoma de México - Comisión Nacional para el Conocimiento y Uso de la Biodiversidad. México, D.F., México. 352 pp. 